\title{
GROUNDWATER VULNERABILITY MAPPING IN FAISALABAD DISTRICT USING GIS BASED DRASTIC MODEL
}

\author{
Aamir Shakoor ${ }^{1}$, , Zahid Mahmood Khan ${ }^{1}$, H. Umar Farid ${ }^{1}$, Muhammad Sultan ${ }^{1, *}$, Aftab Ahmad Khan ${ }^{2}$, Ijaz Ahmad ${ }^{3}$ and \\ Muhammad Azmat ${ }^{4}$ \\ ${ }^{1}$ Department of Agricultural Engineering, Bahauddin Zakariya University, Multan-Pakistan. ${ }^{2}$ GCISC Ministry of Climate Change \\ Islamabad, Pakistan, ${ }^{3}$ Center of Excellence in water resources engineering, UET, Lahore. ${ }^{4}$ Geo-informatics Engineering, National \\ University of Sciences and Technology (NUST), Islamabad-Pakistan.
}

\begin{abstract}
The demand of groundwater has significantly increased during the past two decades to meet the food and fiber requirements due to constrained surface irrigation water. The groundwater has a major share to grow agriculture in Punjab-Pakistan, which produces more than $90 \%$ gains of the country. Beside the importance of groundwater, a major concern in recent years is the contamination of groundwater. The consecutive monitoring and mapping of aquifer water quality in large areas is a hectic job and not even economically feasible. Thus groundwater vulnerability maps are becoming more in demands to represents regional aquifer contamination potential. The aim of this research work was to find out the groundwater vulnerability potential zones in Faisalabad and its nearby areas, which is the fastest growing city of Pakistan. For this purpose, GIS based DRASTIC model was used to measure vulnerability related to agriculture in Faisalabad district. The inputs of the model are based on seven different layers. The results of the model were compared with groundwater samples. It was found that the DRASTIC model accurately identified the vulnerability of Faisalabad District with prediction efficiency of about $73 \%$. The results revealed that more than $30 \%$ of study area was under high vulnerability potential. The areas under high vulnerable pollution are located in middle and upper part of Faisalabad District. The high vulnerable pollution in surrounding of Salarwala, Chak Jhumra and Khurianwala cities was due to shallow groundwater table, high recharge, gradual slope, sandy aquifer media and soil media consist of medium sand. The high vulnerable pollution in surrounding of Dijkot city was due to shallow groundwater table, gradual slope, vadose zone consist of course sand and high hydraulic conductivity. It is therefore recommended that Rainwater harvesting and ASR (Aquifer Storage and Recovery Wells) should be adopted in medium and high vulnerability areas to reduce water salinity.
\end{abstract}

\section{INTRODUCTION}

Groundwater is one of the most important component of our life support system and has significant contribution in economic development (Saatsaz et al., 2011). In recent decades, the utilization of groundwater has remarkably increased. World widely, more than 2 billion people depends upon groundwater to meet drinking water requirements (Senthilkumar et al., 2014), while in Pakistan, 90\% population utilized aquifer water for daily domestic need ( Qureshi et al. 2010).

Irrigated agriculture exists worldwide on about 260 million hectares of land, out of which, four countries i.e. India, China, USA and Pakistan account for more than half of the world's irrigated land (Bhatti et al., 2017; Doll and Siebert, 1999). Globally, irrigated agriculture produces about $60 \%$ of grain production that utilizes two third of world's fresh water for irrigation with a significant contribution from groundwater resources. It was estimated that annually, about 750-800 billion cubic meters of global groundwater withdrawals were being used for irrigated agriculture (Shah, 2007).
Like many other countries of the world, Pakistan depends heavily on irrigated agriculture because of the arid climatic conditions (Javed et al., 2015; Mongat et al., 2015; Asghar et al., 2002). During the drought period, groundwater was the main cause for the survival of irrigated agriculture in Pakistan (Arshad et al., 2013). The use of groundwater is expected to increase further with rising pressure of population to produce more food. About 1.2 million small capacity private tubewells are working in Pakistan, out of which, more than $90 \%$ are used for agriculture (Shakoor et al., 2017; Qureshi, 2012). About 62 billion cubic meter (BCM) of groundwater is being pumped annually to supplement surface water supplies as food demand is increasing in Pakistan due to population growth (Arshad et al., 2013; Shakoor et al., 2012). The tubewells not only provide additional water but also add flexibility to water supplies to match the crop water requirements. Most of tubewell installation has taken place in Punjab due to intensive agricultural development (Arshad et al., 2013). In irrigated agriculture, the application of poor quality groundwater was considered as one of the major source of salinity in root zone and ultimately a reason of reduction in crops yield (Kijne,

*Corresponding author's email: aamirskr@yahoo.com, muhammadsultan@,bzu.edu.pk 
1996; Shakoor et al., 2015). In Punjab, about one fourth of the groundwater has poor quality groundwater, while it is about 3/4 in Sindh (Haider, 2000). In Punjab, the quality of groundwater varies between 0.3 to $4.6 \mathrm{dS} / \mathrm{m}$ (deciSiemens per meter) in the Punjab province.

Currently, several methods have been popular for evaluating groundwater vulnerability (Zhonghua et al., 2015; Ersoy et al., 2013) and DRASTIC is the most widely used approach, which combine physical and hydrogeological characteristics of a specific area (Senthilkumar et al., 2014; Adjim and Bensaoula, 2013; Babiker et al., 2005). DRASTIC method was developed by the staff of the U.S. Agency for Environmental Protection USEPA (Aller et al., 1987). DRASTIC method, a standardized system for evaluating groundwater pollution potential has been frequently implemented (AlAnsari et al., 2013; Saha and Alam, 2014). It allows the assessment of vulnerability of the vertical aquifer pollution caused by parametric systems (Madjid and Omar, 2013). DRASTIC model employs hydro-geological data in a Geographical Information System (GIS) environment to compute aquifer vulnerability index. DRASTIC is an shortening of seven physical parameters of hydrogeological which used to define groundwater system and its susceptibility towards pollution (Zhonghua et al., 2015; Pradhan et al., 2014; Rahman, 2008; Jamrah et al., 2007). It considers seven parameters, which taken together, provide the acronym such as Depth to groundwater (D), Recharge (R), Aquifer type (A), Soil type (S), Topography (T), Impact of the vadose zone (I), Hydraulic conductivity
(C) (Hanini et al., 2013). Each parameter, divided to an interval of significant values, is assigned by a numerical rating based on its growing importance in the vulnerability. These seven parameters are used to define the different hydrogeological units, variously influenced by transport processes and attenuation of contaminants in the soil (Madjid and Omar, 2013; Khan et al., 2010).

Groundwater vulnerability is sensitive to humans and natural impacts on the ground surface and within the aquifer system and consider and thus indispensable property of groundwater. The regional groundwater management and protection from contamination can be achieved by vulnerability zone maps. For this purpose, the area of Faisalabad district was selected, one of the largest growing cities of Pakistan, to delineate the groundwater vulnerability zones. The specific objectives of this study were to conceptualize a method to identify the groundwater vulnerability and to delineate the groundwater vulnerable zones in the Faisalabad District.

\section{MATERIALS AND METHODS}

Study Area: This research work was conducted at Faisalabad district, which covers the area of $5856 \mathrm{~km}^{2}$. Geographically, Faisalabad district is situated in $30.68^{\circ} \mathrm{N}$ $72.85^{\circ} \mathrm{E}$ to $31.76^{\circ} \mathrm{N} 73.21^{\circ} \mathrm{E}$ with an elevation of $184.14 \mathrm{~m}$ (604 feet) above sea level and is located in the Punjab province, as shown in Figure 1.

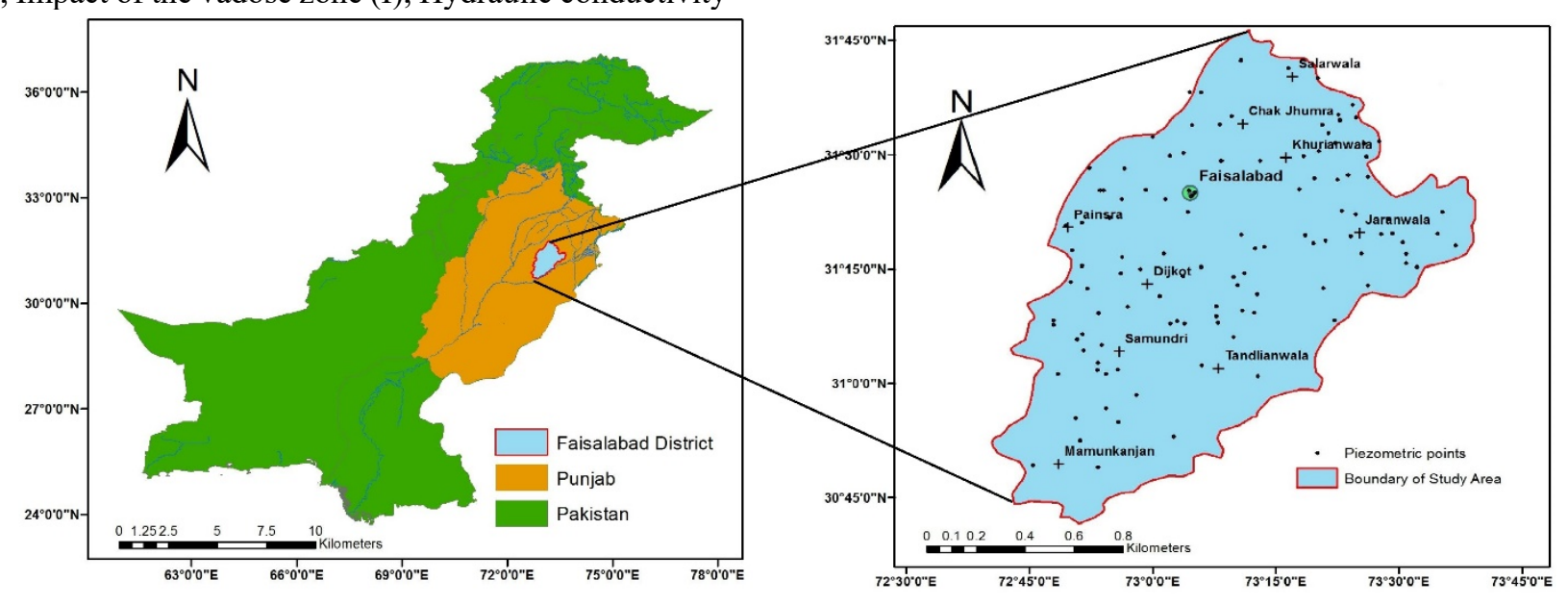

Figure 1: Location of study area and piezometers

The climate of Faisalabad is arid climate in which summer is extremely hot with temperature variation of 21 $51^{\circ} \mathrm{C}$, while in winter season is $7-27^{\circ} \mathrm{C}$. The surface elevation data were downloaded from ASTER GDEM Worldwide Elevation Data (1.5 arc-second Resolution) using Global Mapper software. Global Mapper is one of the most widely used software for reading large amounts of geospatial data in native format (Korzeniowska, 2012; Cliffen and Weeden, 2009). The specific latitude/ longitude bound of the area extracted using Global Mapper (version 13.2) in decimal degree. The file was saved in Raster file (BIL format). The data were processed and the model area was clipped using GIS software, as shown in Figure 2. The higher elevation $(271 \mathrm{~m})$ was found in northeast side and comparative lower elevation (164m) was found in southwest side of the study area.

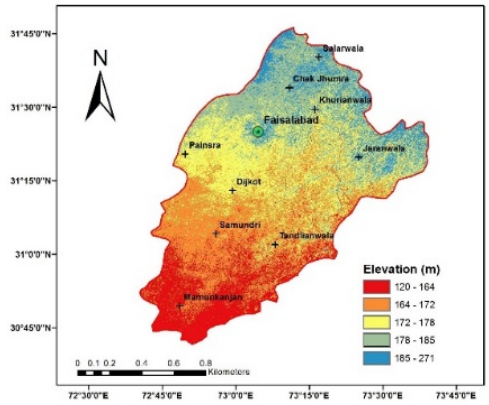

Figure 2: Elevation of District Faisalabad 


\subsection{Description of DRASTIC Model}

The DRASTIC is GIS based model which required seven layers of different hydrogeological data of a particular area. The acronym DRASTIC represents to the letters of the seven base maps (Figure 3).

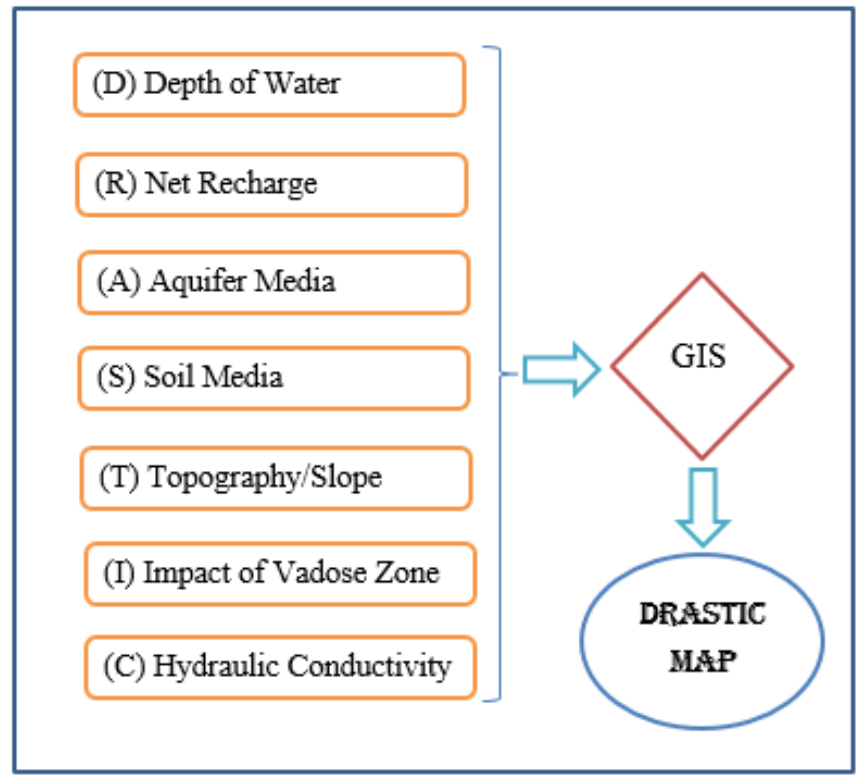

Figure 3: Seven parameters and layers of DRASTIC model

The final vulnerability DRASTIC indexed (Di) map is computed by weighted sum overlay technique of all seven layers in GIS using the Equation 1 (Shirazi et al., 2012):

\subsection{DRASTIC index $\left(D_{i}\right)=\operatorname{DrDw}+\operatorname{RrRw}+\operatorname{ArAw}+$ $\mathrm{SrSw}+\mathrm{TrTw}+\mathrm{Irlw}+\mathrm{CrCw}$ (Eq. 1)}

Where, D, R, A, S, T, I, and $\mathrm{C}$ are the seven different hydro-geological parameters, $r$ is the user defined rating values of each range, and $\mathrm{w}$ is the fixed weight assigned to each layer parameter (Table 1). The weight of each parameter in the model is fixed, higher weight indicates the relative higher influence of the parameter in transportation of pollution to the groundwater. The rating of each parameters are variable, depending on the features and variability of the study site (Dixon, 2005).

Table 1. The seven DRASTIC model parameters and their relative weights

\begin{tabular}{|c|c|c|c|}
\hline Factors & Descriptions & $\begin{array}{l}\text { Original } \\
\text { Relative } \\
\text { Weight }\end{array}$ & $\begin{array}{l}\text { Modified } \\
\text { Relative } \\
\text { Weight* }\end{array}$ \\
\hline Depth to Water & $\begin{array}{l}\text { Represents the depth from the ground surface to the water table, deeper } \\
\text { water table levels imply lesser chance for contamination to occur. }\end{array}$ & 5 & 5 \\
\hline Net Recharge & $\begin{array}{l}\text { Represents the amount of water which penetrates the ground surface } \\
\text { and reaches the water table, recharge water represents the vehicle for } \\
\text { transporting pollutants. }\end{array}$ & 4 & 4 \\
\hline Aquifer Media & $\begin{array}{l}\text { Refers to the saturated zone material properties, which controls the } \\
\text { pollutant attenuation processes. }\end{array}$ & 3 & 3 \\
\hline Soil Media & $\begin{array}{l}\text { Represents the uppermost weathered portion of the unsaturated zone } \\
\text { and controls the amount of recharge that can infiltrate downward. }\end{array}$ & 2 & 5 \\
\hline Topography & $\begin{array}{l}\text { Refers to the slope of the land surface, it dictates whether the runoff will } \\
\text { remain on the surface to allow contaminant percolation to the saturated } \\
\text { zone. }\end{array}$ & 1 & 3 \\
\hline $\begin{array}{l}\text { Impact of } \\
\text { Vadose Zone }\end{array}$ & $\begin{array}{l}\text { Is defined as the unsaturated zone material, it controls the passage and } \\
\text { attenuation of the } 2 \text { contaminated material to the saturated zone. }\end{array}$ & 5 & 4 \\
\hline $\begin{array}{l}\text { Hydraulic } \\
\text { Conductivity }\end{array}$ & $\begin{array}{l}\text { Indicates the ability of the aquifer to transmit water, hence determines } \\
\text { the rate of flow of contaminant material within the groundwater system. }\end{array}$ & 3 & 2 \\
\hline
\end{tabular}

Source Dixon (2005)

Groundwater Data: The data of groundwater level were acquired from the Department of Irrigation and Drainage Faisalabad for the years of 2014-2015. The 
groundwater samples were collected from 40 tubewells across the study area for determining groundwater quality. In order to do so, the water analysis were performed in the Water Quality \& Environmental Engineering Lab, Dept. of Agricultural Engineering, Bahauddin Zakariya University, Multan.

Rainfall Data: In this study a total of 55 rain gauge stations were used for temporal analysis of rainfall data, acquired from Pakistan Metrological Department (PMD), Islamabad for year 2016 TRMM Satellite rainfall data at monthly (TRMM 3B43 V6) and daily (TRMM 3B42 V6) time steps for the year 2016 were collect from (http://neo.sci.gsfc.nasa.gov/Search.html?group=39)

NASA public domain. The cumulative annual rainfall was occurred in the range of $932-1091 \mathrm{~mm}$ (Figure 4). The maximum rainfall was occurred on the upper side of the area.

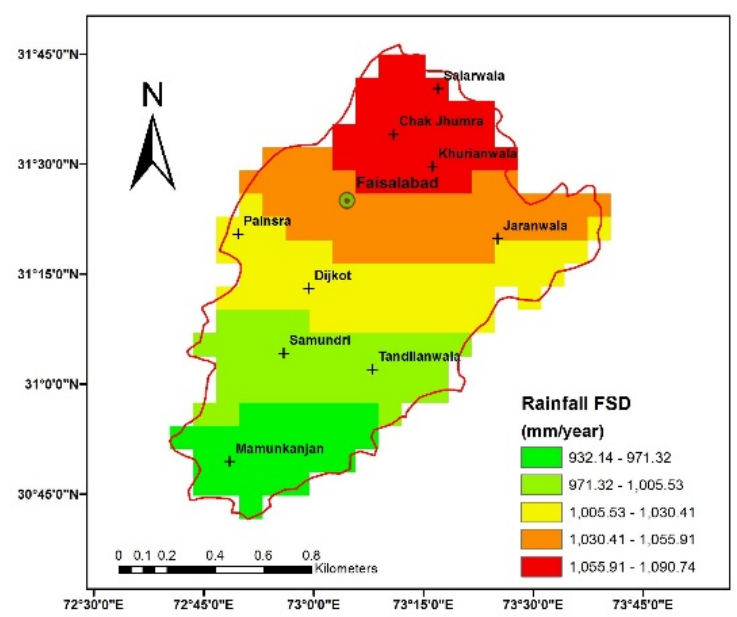

Figure 4: Rainfall distribution in the study area

Table 2: DRASTIC parameters and percent area

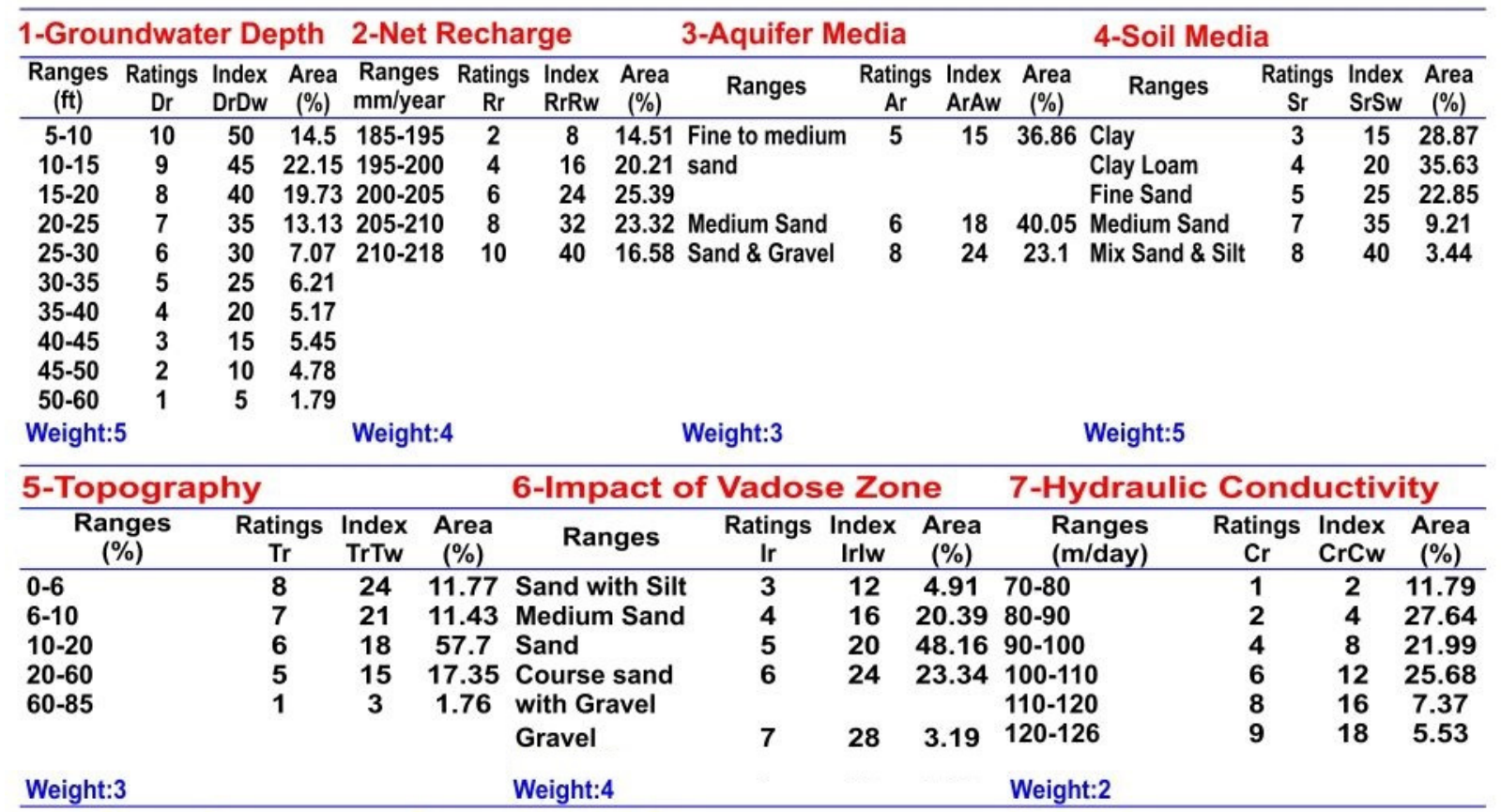

\subsection{Lithological Data}

Water and Power Development Authority (WAPDA, 1978) conducted a study at Rechna Doab which contained the data of 487 boreholes to determine the sub-surface lithology and aquifer characteristics. The lithological data thus were collected from WAPDA. The boreholes depth were from 91 to $457 \mathrm{~m}$ below the land surface. These are river transported deposits (alluvium), which are quite thick and fairly homogeneous in extent. The analysis showed that the soils had different classification according to different textural characteristics. The soil texture class includes: Fine (Sandy Clay, Silty Clay and Clay), Moderately Fine (Sandy Clay Loam, Clay Loam and Silty Clay Loam), Medium (Loam, Silt Loam and Silt), Moderately Coarse (Sandy Loam, Fine Sandy Loam) and Coarse (Sandy Loam, Sand). The soils consist of alluvial deposits transported by the Indus River and its tributaries. The surface soils textures are predominantly fine and moderately medium, with favorable permeability characteristics and are similar throughout the area.

Model Validation: The model was validated by comparing the predicted values with the values of monitoring wells. The vulnerability index values of model were converted from raster to point values using the Raster to Point conversion tool and the point values were compared with the water samples. The prediction accuracy rate was determined by whether the model successfully identified a low vulnerability area for a low irrigation water quality observation and a high vulnerability area for a high water quality observations with respect to salinity.

\section{RESULTS AND DISCUSSIONS}




\subsection{Depth to Groundwater}

The depth of groundwater level from the ground surface is one of the significant factor in the model because it describes the downward traveling distance of the leaching contamination before mixing in the groundwater. This factor also depicts the potential of interaction between the deep percolated pollution and groundwater. The shallow groundwater depth generally has higher potential of

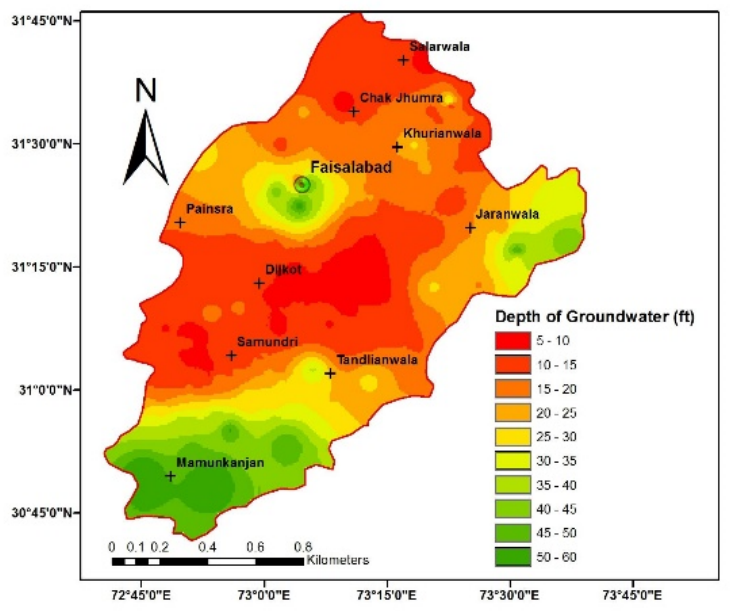

pollution from the ground surface. The maps of borehole data were contoured by interpolating and presented in Figure 5. The interval of groundwater water, rating, weight and resulted index for water table are given in Table 2. The water table depth is ranged from $5 \mathrm{ft}$ to $60 \mathrm{ft}$ and divided into ten categories with interval of $5 \mathrm{ft}$. The comparative deep water level is present around Faisalabad, Mamunkajan and Jaranwala cities and has less potential of contamination and vice versa.

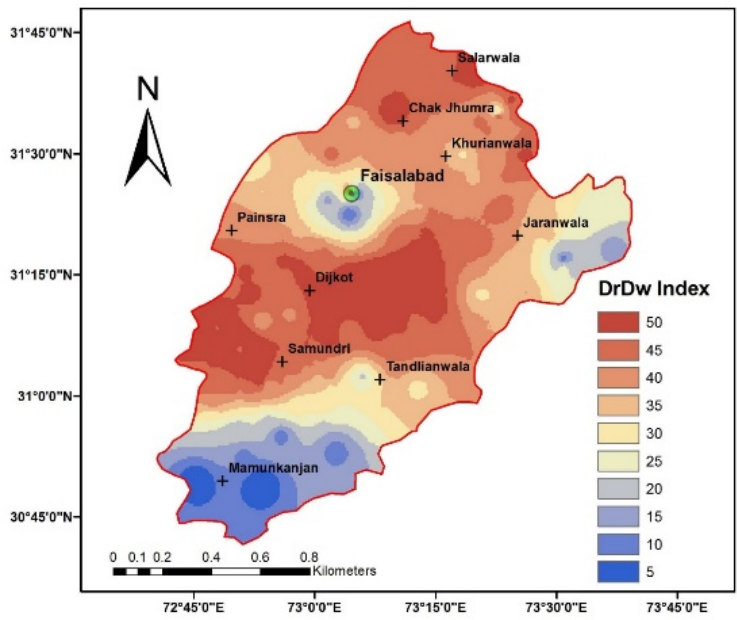

Figure 5: Spatial distribution of groundwater depth and DrDw index

\subsection{Net Recharge}

The total amount of rainfall is consider as net recharge to groundwater and work as vehicle to transport

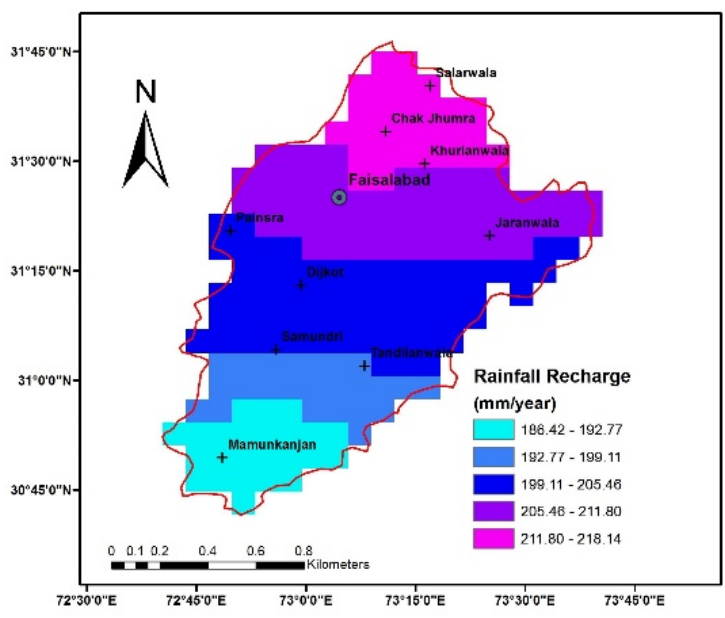

contamination from ground surface to saturated aquifer. The estimation of recharge is complicated and involves a number of unknown factors, which made the estimation difficult. Sources of recharge to groundwater include infiltration from rainfall and losses from irrigated fields.

Figure 6: Spatial distribution of recharge and RrRw index

The rainfall recharge data were collected from the Satellite based (TRMM) data and spatial distribution is presented in Figure 6. The upper part of the study area has higher level of risk because higher recharge reached more quickly from ground surface to groundwater. An area receive low groundwater recharge is has less potential to carry pollution because of the minimum permeable pathway from the ground surface to the groundwater (Table 2). Ahmed and Chaudhry (1988) conducted a field study to determine the recharge contribution to groundwater from rainfall and water delivered in

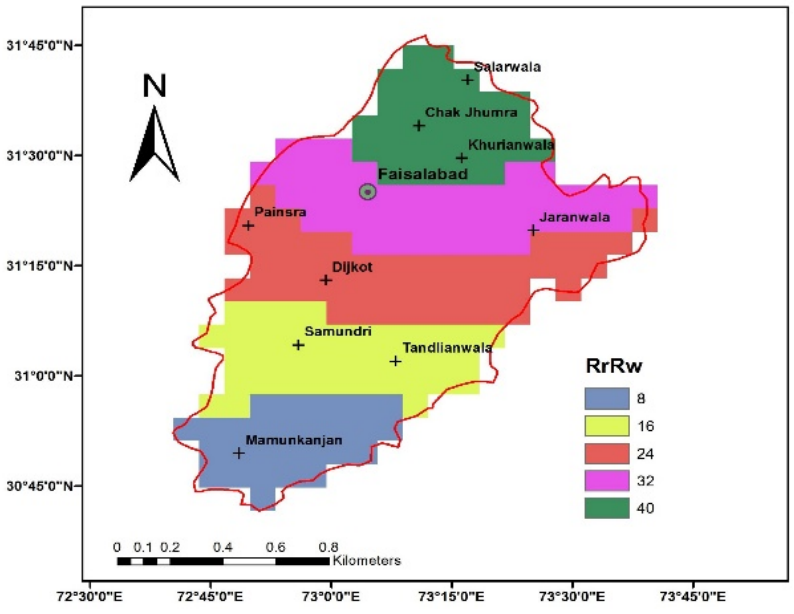

irrigation fields in Upper Gogera Branch canal, Punjab, Pakistan. The contribution of recharge to groundwater was found from 17 to $22 \%$ of rainfall, while $20 \%$ was selected as used by Arshad et al. (2005), conducted a field and modeling study in Rechna Doab, Punjab, Pakistan.

\subsection{Aquifer Media}

The movement of salinity in groundwater is strongly depend upon the aquifer media and it describe the time for intrusion process such as diffusion, advection and 
dispersion with or without sorption effects. Aquifer media provides the interconnected pore spaces to solute transport

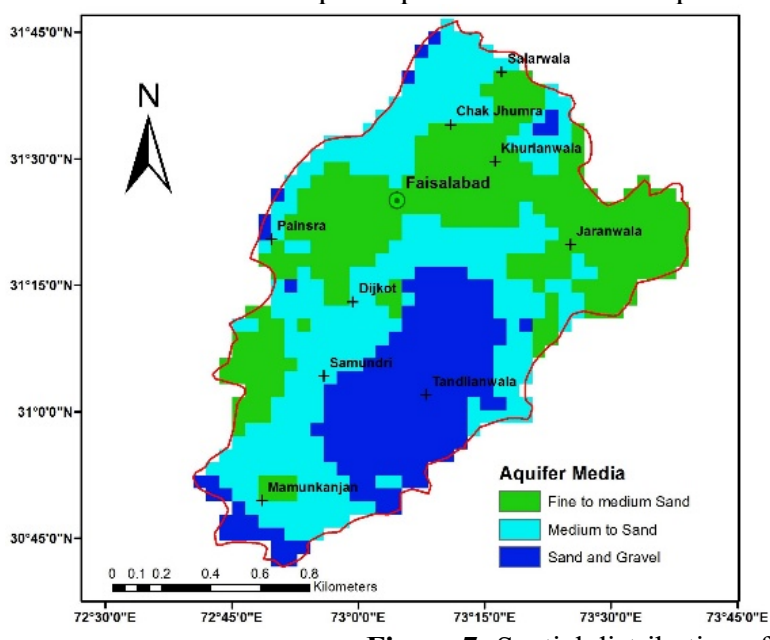

Figure 7: Spatial distribution of

According to the geological data of District Faisalabad, the aquifer was classified as Fine to Medium Sand, Medium to sand and Sand to Gravel and rating of aquifer media is from 5 to 8 (Table 2). The higher rating was given to Sand and gravels and the spatial distribution of aquifer media is shown in Figure 7.

\subsection{Soil Media}

The type and gain size in the soil are the main factor for potential of pollution of soil media. The characteristics of

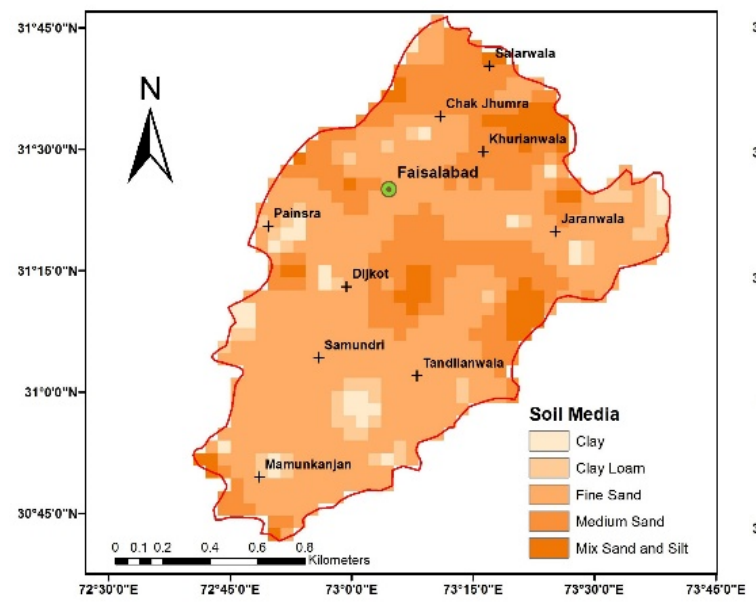

Figure 8: Spatial distribution of soil media and $\mathrm{SrSw}$ index

to gravity and hence it allow less amount of water to infiltrate or recharge. To prepare the topographic map, the specific latitude/ longitude bound of the area extracted using Global Mapper (version 13.2) and file was saved in Raster file (BIL format). The data were processed using slope calculation tool in GIS software and clipped from the model, as shown in Figure 9.

from one place to other. Thus the movement of

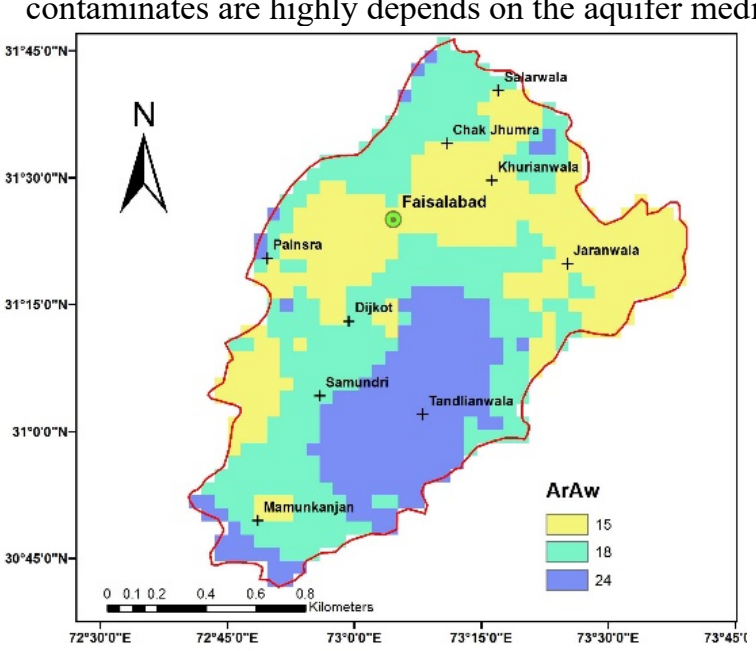

upper soil layer will define the amount of water infiltrating from the ground surface and purifying process of contaminants. The presence of clay and silt particles in the soil decreases infiltration rate and forbid contaminant migration via physico-chemical processes, i.e., ionic exchange and absorption. The weightage of 5 and ratings from 3-8 were assigned to prepared a soil media map (Table 2). The majority of the Soil varies from Clay to Fine Sand in the study area (Figure 8). In comparison to fine soil media, coarse soil media have high rates because it has high potential to infiltrate contamination from ground surface.

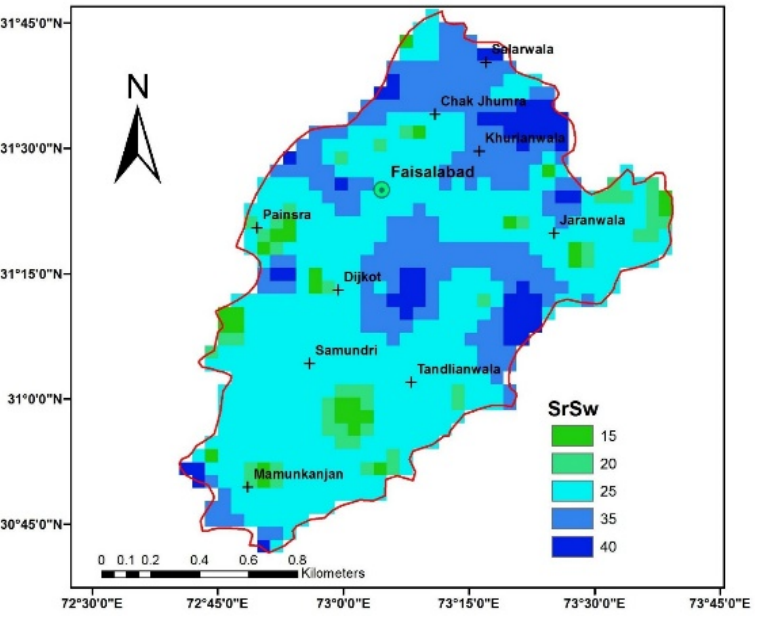

Topography generally describe the slope of an area. In less slope areas the potential of contamination is high because it allow water to stand for longer period of time and hence greater recharge occurred which can carry pollution. In steep slopes areas, larger amount of water has runoff due 

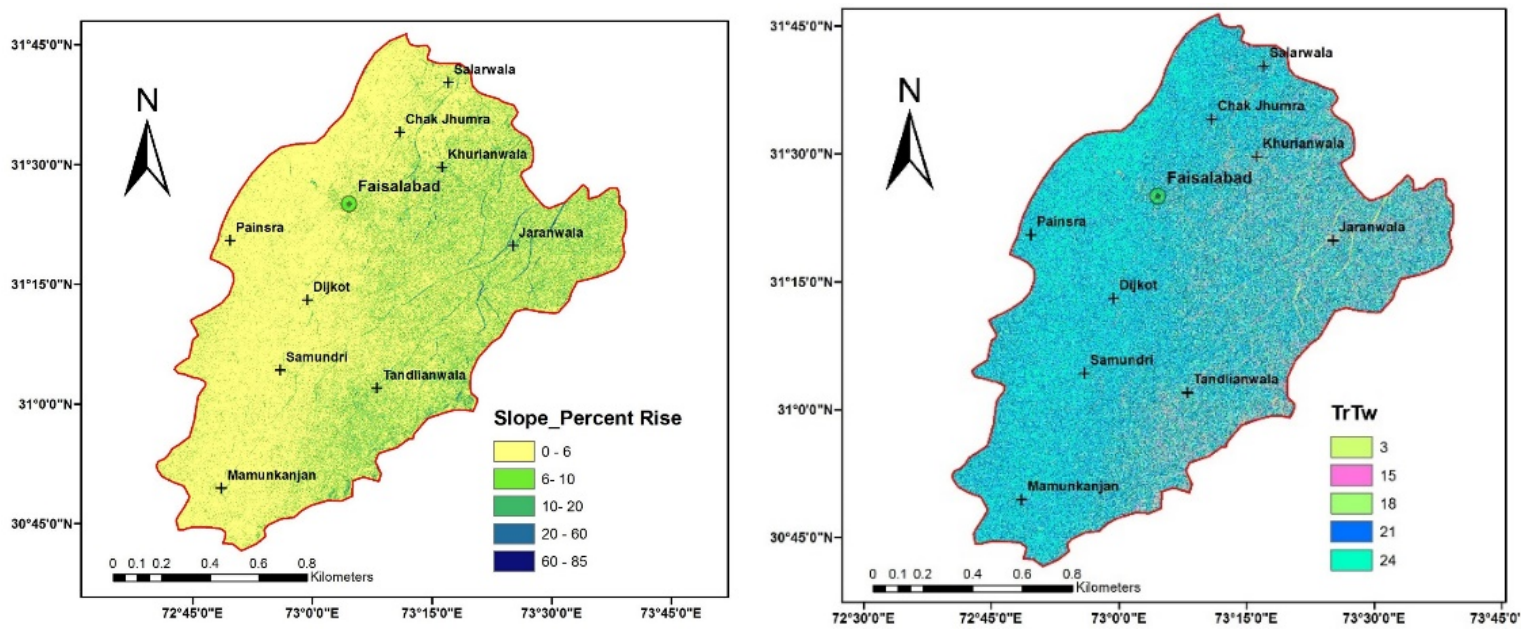

Figure 9: Spatial distribution of slope and TrTw

\subsection{Impact of Vadose Zone}

The vadose zone's influencing and essential component for determining potential of aquifer pollution. The impact of vadose zone to groundwater vulnerability is the combination characteristics of topography and aquifer media. Vadose zone layer is the in between the saturated and unsaturated aquifer and has great influence on solute transport. Impact of vadose zone map was delineated from the analysis of lithological data of the study area. The vadose zone has a high impact on water movement if it is composed of a permeable material. The weights and ratings for the vadose zone are shown in Table 2. Vadose zones have been mapped as shown in Figure 10.
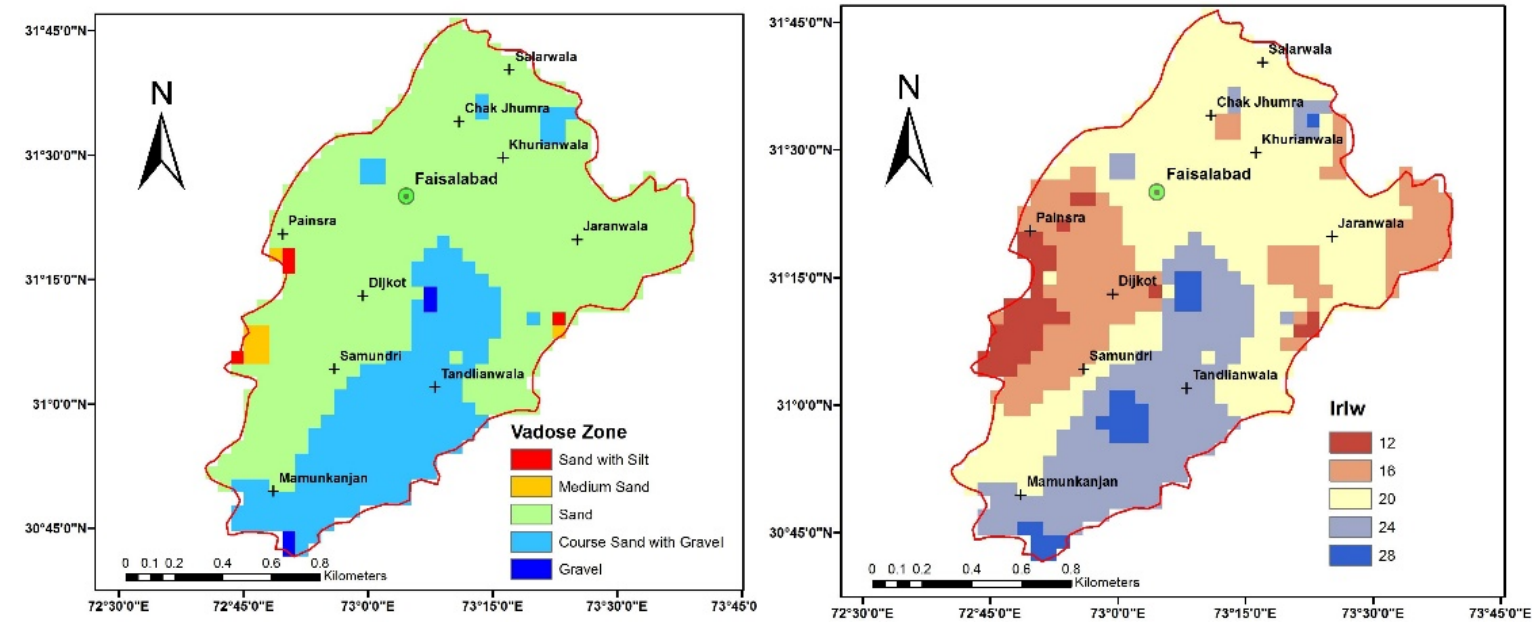

Figure 10: Spatial distribution of vadose zone and IrIw

\subsection{Hydraulic Conductivity}

The ability of aquifer media to transmit water within its saturated profile is known to be hydraulic conductivity. It is largely influenced by the effective porosity of the aquifer, is the amount of actual interconnected pore spaces takes part to transmit water. Higher hydraulic conductivity allows water flux to carry solute from higher to lower contamination zone, hence more vulnerable. The hydraulic conductivity of the study area was calculated from the soil data according to CSIRO (2003) and map to represent spatial distribution of hydraulic conductivity was prepared. The range of hydraulic conductivity is between $71 \mathrm{~m} /$ day to $126 \mathrm{~m}$ /day in the study area. The ratings for hydraulic conductivity are from 1-9, depending upon the hydraulic conductivity, shown in Table 2 . The spatial delineation of hydraulic conductivity and its index is shown in Figures 11. 

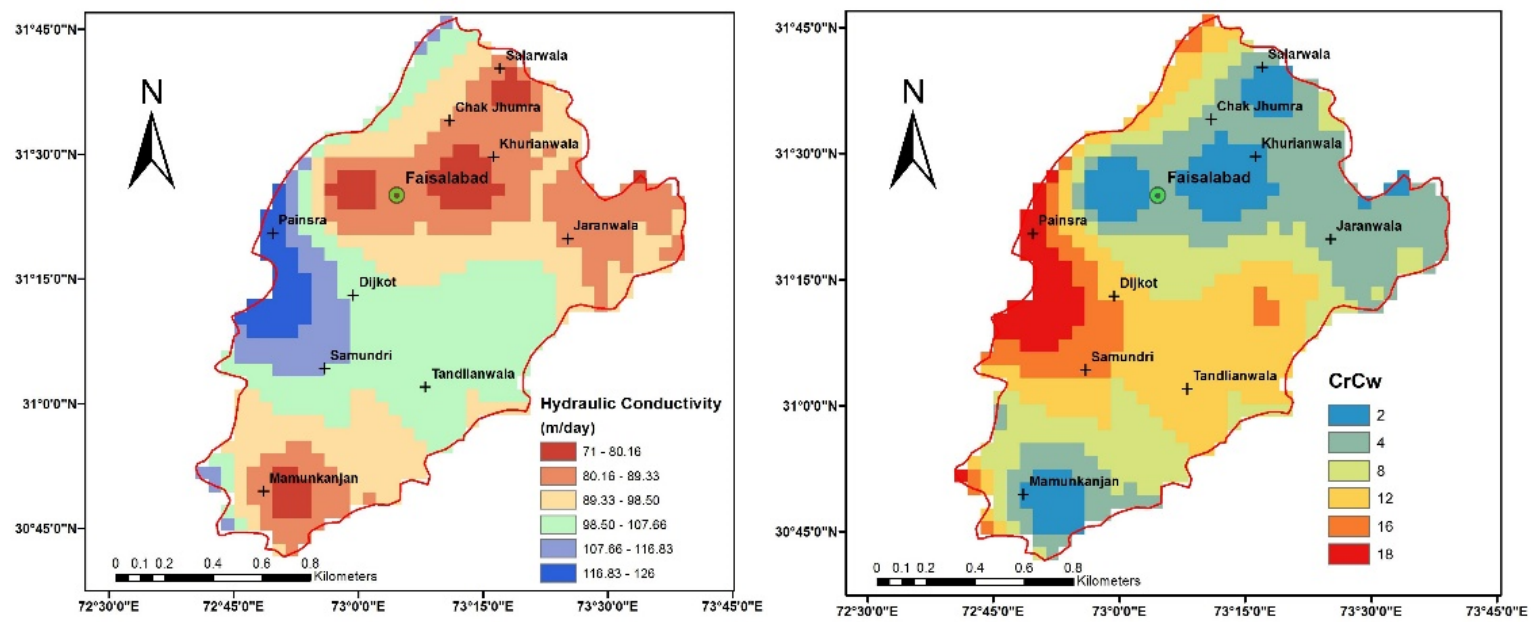

Figure 11: Spatial distribution of hydraulic conductivity and $\mathrm{CrCw}$

\subsection{Vulnerability Zones}

All these seven hydro-geological data layers of DRASTIC model were sum up in ArcGIS environment using weighted sum overlay analysis to delineate vulnerability map. In this final index map, the value of each cell was computed as the sum of all the assigned indexes which ranged from 94 to 200. Finally, vulnerability layer was further reclassified into three classes i.e., low vulnerable (94-139), moderate vulnerable (139-167) and high vulnerable (167-200) zones (Table 3). The results revealed

Table 3: Area under vulnerability to groundwater pollution

\begin{tabular}{|c|c|c|c|}
\hline Vulnerability & $\begin{array}{c}\text { Vulnerability } \\
\text { Index Range }\end{array}$ & Area (Ha) & Area (Percent) \\
\hline Low & $94-139$ & 1287.52 & 22.00 \\
\hline Moderate & $139-167$ & 2787.86 & 47.60 \\
\hline High & $167-200$ & 1780.61 & 30.40 \\
\hline
\end{tabular}

that an area of about $1287.52 \mathrm{~km}^{2}$ is in the low vulnerable zone, about $2787.86 \mathrm{~km}^{2}$ are in the moderately vulnerable zone and about $1780.61 \mathrm{~km}^{2}$ are in the high vulnerability zone with a DRASTIC index ranging between 167 and 200. This means that more than one third of the Faisalabad District's groundwater is at high risk in terms of agricultural pollution potential and about half of area in moderate pollution potential. The areas under high vulnerability zone is mainly in the North and Central parts of the study area, where different physical factors supporting the chances of getting aquifer water polluted. 


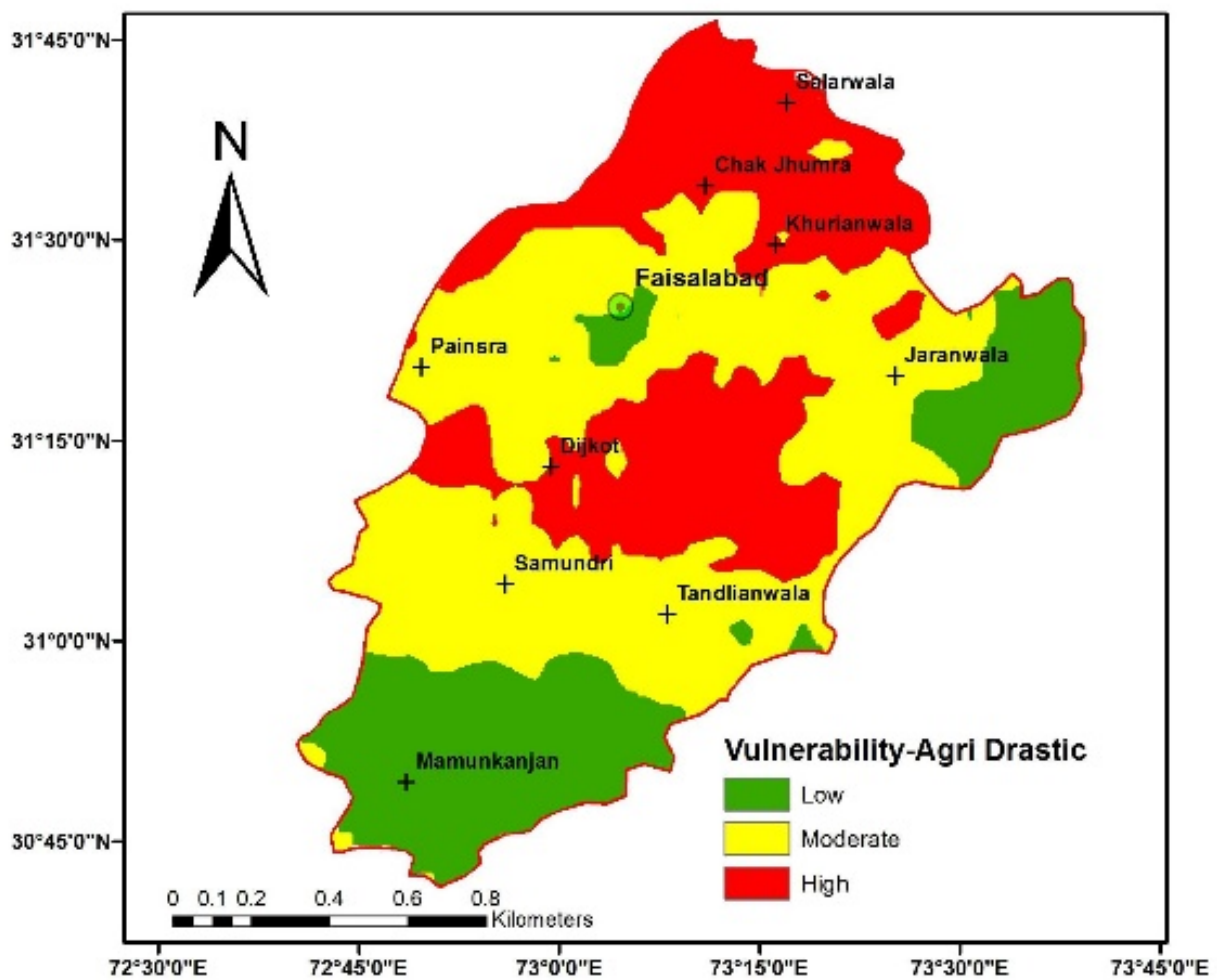

Figure 12: Groundwater vulnerability map

The spatial distribution of groundwater vulnerability based on agricultural pint of view is shown in Figure 12. The areas, which are under the high vulnerable pollution, are in surrounding of Salarwala, Chak Jhumra, Khurianwala, Dijkot, Satiana, Tandalianwala cities which is mainly due to following 5 reasons particularly for that area, such as 1) shallow groundwater table, which imply higher chance for contamination to occur because contamination reached rapidly to it. 2) high recharge, which paly as the vehicle for transporting pollutants from the surface 3) lesser slope, which help water to infiltrates more than runoff 4) coarse sand aquifer media which has high potential of groundwater intrusion and movement 5) higher hydraulic conductivity, which transmit more contaminated water within the groundwater system. The areas having moderate vulnerability are in surrounding of Faisalabad, Painsra, Samundri, Jaranwala cities. The remaining areas such as Jaranwala and Mamukanjan has low groundwater vulnerability. The major limitation of
DRASTIC approach is that it can be used to any pollutant which leached from ground surface to water level but it does not produce a clear picture of the pollution potential of individual chemical.

\subsection{Model Validation}

The model was validated by comparing the predicted values with the values of monitoring wells. The vulnerability index values of model were converted from raster to point values using the Raster to Point conversion tool and the point values were compared with the water samples. The prediction accuracy rate was determined by whether the model successfully identified a low vulnerability area for a low irrigation water quality observation and a high vulnerability area for a high water quality observations with respect to total dissolved solid (TDS). The results of predicted water TDS and model prediction vulnerability are depicted in Table 3.

Table 3: Model prediction results

\begin{tabular}{|c|c|c|c|c|c|c|c|}
\hline $\begin{array}{c}\text { Well } \\
\#\end{array}$ & $\begin{array}{c}\text { TDS (mg/L) } \\
\text { Observation }\end{array}$ & $\begin{array}{c}\text { Model } \\
\text { Predicted } \\
\text { Vulnerability }\end{array}$ & $\begin{array}{c}\text { Accuracy } \\
\text { (True=1, } \\
\text { False=0) }\end{array}$ & $\begin{array}{c}\text { Well } \\
\#\end{array}$ & $\begin{array}{c}\text { TDS (mg/L) } \\
\text { Observation }\end{array}$ & $\begin{array}{c}\text { Model } \\
\text { Predicted } \\
\text { Vulnerability }\end{array}$ & $\begin{array}{c}\text { Accuracy } \\
\text { True=1, } \\
\text { False=0) }\end{array}$ \\
\hline W1 & 2560 & High & 1 & W21 & 4416 & Medium & 0 \\
\hline W2 & 4480 & Medium & 1 & W22 & 5888 & Medium & 0 \\
\hline W3 & 2624 & High & 1 & W23 & 512 & Low & 1 \\
\hline W4 & 3264 & High & 1 & W24 & 960 & Low & 1 \\
\hline W5 & 2176 & Medium & 0 & W25 & 640 & Low & 1 \\
\hline W6 & 1664 & Medium & 1 & W26 & 3776 & Medium & 0 \\
\hline W7 & 1856 & Medium & 0 & W27 & 576 & Low & 1 \\
\hline W8 & 8320 & High & 1 & W28 & 1984 & Low & 1 \\
\hline W9 & 1984 & Medium & 0 & W29 & 2496 & Medium & 0 \\
\hline W10 & 1088 & Low & 0 & W30 & 583 & Low & 1 \\
\hline
\end{tabular}




\begin{tabular}{|c|c|c|c|c|c|c|c|} 
W11 & 2240 & High & 1 & W31 & 605 & Low & 1 \\
\hline W12 & 1600 & Medium & 1 & W32 & 704 & Low & 1 \\
\hline W13 & 1336 & Medium & 1 & W33 & 2944 & Medium & 0 \\
\hline W14 & 5568 & High & 1 & W34 & 2432 & High & 1 \\
\hline W15 & 4992 & High & 1 & W35 & 1664 & Medium & 1 \\
\hline W16 & 4480 & High & 1 & W36 & 512 & Low & 1 \\
\hline W17 & 1496 & Medium & 1 & W37 & 1024 & Medium & 1 \\
\hline W18 & 1216 & Medium & 1 & W38 & 356 & Low & 1 \\
\hline W19 & 728 & Low & 1 & W39 & 3648 & Medium & 0 \\
\hline W20 & 5120 & Medium & 0 & W40 & 192 & Low & 1 \\
\hline
\end{tabular}

The groundwater quality of fresh and saline water for total dissolved solid were formulated according to criteria (Good: < 1000mg/L, Marginal: 1000-1800mg/L and Hazardous: $>1800 \mathrm{mg} / \mathrm{L}$ ) as described by WAPDA (1982) for irrigation water. The accuracy was calculated with True and False with values of 1 and 0 , respectively. It was found that 29 samples out of 40 for TDS satisfied the model results with prediction efficiency of $72.5 \%$.

\section{CONCLUSIONS}

In this research work, a GIS based DRASTIC model was employed to measure the agricultural groundwater vulnerability of Faisalabad district. Seven different hydrogeological layers according to model were used to represent the pollution potential. In final map, the DRASTIC index ranges from 94 to 200 and it was further reclassified into three sub-classes such as Low vulnerable (94-139), Moderate vulnerable (139 to 167) and High vulnerable (167 to 200$)$. The final vulnerability map represents the areas which could be more disposed to groundwater contaminations relative to one another. The main conclusions drawn from the research were as follows:

- The DRASTIC model accurately identified the vulnerability of Faisalabad District with prediction efficiency of about $73 \%$.

- The areas under high vulnerable pollution are located in middle and upper part of Faisalabad District.

- The high vulnerable pollution in surrounding of Salarwala, Chak Jhumra and Khurianwala cities was due to shallow groundwater table, high recharge, gradual slope, sandy aquifer media and soil media consist of medium sand.

- The high vulnerable pollution in surrounding of Dijkot city was due to shallow groundwater table, gradual slope, vadose zone consist of course sand and high hydraulic conductivity.

It is recommended that,

- Proper drainage system should be prepared in high vulnerable areas for avoiding water contamination.

- Rainwater harvesting and ASR (Aquifer Storage and Recovery Wells) should be adopted in medium and high vulnerability areas to reduce water salinity.

- This kind of study should be conducted in all major districts of Pakistan for future planning to protect groundwater resources.

\section{ACKNOWLEDGMENTS}

The Principle Investigators are highly thankful to Higher Education Commission Pakistan for funding this project under Startup Research Grant Program (HEC_SRGP \# 714).

\section{REFERENCES}

1. Adjim, M., and F. Bensaoula (2013). Application of the Drastic Groundwater Vulnerability Mapping to the Aquifer of Maghnia (North-West of Algeria). Larhyss Journal, 16: 21-30.

2. Ahmed, N. and G.R. Chaudhary. 1988. Irrigated Agriculture of Pakistan, 61-B/2, Gulberg III, Lahore, Pakistan

3. Al-Ansari, N.A., A. M. Al-Rawabdeh, A. A. AlTaani and S. Knutsson (2013). "A GIS-Based Drastic Model for Assessing Aquifer Vulnerability in Amman-Zerqa Groundwater Basin, Jordan". Engineering, Vol. 5: 490-504.

4. Aller, Linda, Todd Bennett, Jay H. Lehr, and Richard J. Petty. 1987. DRASTIC--a Standardized System for Evaluating Ground Water Pollution Potential Using Hydrogeologic Settings. EPA/600/2-85/018, US Environmental Protection Agency, Robert S. Kerr Environmental Research Laboratory, Office of Research and Development.

5. Arshad, M., A. Shakoor, I. Ahmad and M. Ahmad. 2013. Vertical Electric Sounding Method for Hydraulic Transmissivity Determination in Comparison with Traditional Methods for Groundwater Exploration. Pak. J. Agri. Sci., 50(3): 487-492.

6. Asghar, M.N., S.A. Prathapar and M.S. Shafique. 2002. Extracting relatively-fresh groundwater from aquifer underlains by salty groundwater. Agri. Water Mange., 52:119-137.

7. Babiker, Insaf S, Mohamad A.A Mohamed, Tetsuya Hiyama, and Kikuo Kato. 2005. "A GIS-based DRASTIC model for assessing aquifer vulnerability in Kakamingahara Heights, Gifu Prefecture, central Japan." Science of the Total Environment 345 127140. 
8. Dixon, B., (2005). "Groundwater vulnerability mapping: A GIS and fuzzy rule based integrated tool”. Applied Geography, Vol. 25: 327-347.

9. Doll, P., and S. Seibert, 1999. A digital global map of irrigated area. Report A 9901, Center for Environmental Research, University of Kassel, Kurt Wolters Strasse 3, 34109 Kassel Germany. pp. 1-45.

10. Ersoy, A.F., and F. Gültekin (2013). DRASTICBased Methodology for Assessing Groundwater Vulnerability in the Gümüşhacıköy and Merzifon Basin, Amasya, Turkey. Earth Sci. Res. SJ. Vol. 17(1): $33-40$.

11. Haider, G (2000). In: Proc. of the international conference on regional groundwater management October, 9-11, Islamabad, Pakistan.

12. Hanini, E.A., A. Added and S. Abdeljaoued (2013). "A GIS-Based DRASTIC Model for Assessing Phreatic Aquifere of Bekalta (Tunisian Sahel)". Journal of Geographic Information System, Vol. 5: 242-247.

13. Jamrah, A., A. Al-Futaisi, N. Rajmohan and S. AlYaroubi (2007). Assessment of Groundwater Vulnerability in the Coastal Region of Oman Using DRASTIC Index Method in GIS Environment. Environ Monit Assess 147:125-138.

14. Javed, Q., M. Arshad, A. Bakhsh, A. Shakoor, Z.A. Chatha and I. Ahmad. 2015. Redesigning of drip irrigation system using locally manufactured material to control pipe losses for orchard. Pak. j. Life Soc. Sci., 13(1):16-19.

15. Khan, M.M.A., R. Umar, and H. Lateh (2010). "Assessment of aquifer vulnerability in parts of Indo Gangetic plain, India". International Journal of the Physical Sciences, Vol. 5(11): 1711-1720.

16. Kijne, J.W. 1996. Water and Salinity Balances for Irrigated Agriculture in Pakistan. Research Paper 5, International Irrigation Management Institute, Colombo, Sri Lanka

17. Madjid, A.B and S. Omar (2013). “Assessment of Groundwater Pollution by Nitrates Using Intrinsic Vulnerability Methods: A Case Study of the Nil Valley Groundwater (Jijel, North-East Algeria)". African Journal of Environmental Science and Technology, Vol. 7(10): 949-960.

18. Mongat, A.S., M. Arshad, A. Bakhsh, A. Shakoor, L. Anjum, U. Kalsoom and F. Shamim 2015. Design, installation and evaluation of solar drip irrigation system at Mini Dam command area. Pak. J. Agri. Sci., 52(2): 384-390.

19. Pradhan, A., A. Neshat and M. Dadras (2014). Groundwater Vulnerability Assessment Using an Improved DRASTIC Method in GIS, Resources, Conservation and Recycling, Vol. 86:74-86.

20. Qureshi, A.S. 2012. Groundwater management in Pakistan: The question of balance. Centenary Celebration (1912 - 2012), Paper No.717:207-217.

21. Qureshi, A.S., P.G. McCornick, A. Sarwar and B.R. Sharma, 2010. Challenges and prospects for sustainable groundwater management in the Indus Basin, Pakistan. Water Resour. Manage., 24(8):1551-1569.
22. Rahman, A., (2008). "A GIS Based DRASTIC Model for Assessing Groundwater Vulnerability in Shallow Aquifer in Aligarh, India”. Applied Geography, Vol. 28: 32-53.

23. Saatsaz, M., M. Chitsazan, S. Eslamian and W.N.A Sulaiman. 2011. The application of groundwater modelling to simulate the behavior of groundwater resources in the Ramhormooz Aquifer, Iran. Int. J. Water, 6 (1/2):29-42.

24. Saha, D. and F. Alam (2014). "Groundwater Vulnerability Assessment Using DRASTIC and Pesticide DRASTIC Models in Intense Agriculture Area of the Gangetic Plains, India". Environ Monit Assess, Vol. 186: 8741-8763.

25. Scott, H.D., Smith, P.A., and Spradley, P. (1992). Using DRASTIC and pesticide usage to determine potential locations of pesticides in ground water in Arkansas. Fayetteville, AR: Arkansas Association of Pesticide Applicators.

26. Senthilkumar, P., J. Nithya, and S.S Babu. (2014). Assessment of Groundwater Vulnerability in Krishnagiri District, Tamil Nadu, India Using DRASTIC Approach. Intl. J. Innovative Research Sci, Engg and Tech. Vol. 3 (3): 10544-10553.

27. Shah, T. 2007. The groundwater economy of SouthAsia: An assessment of size, significance and socioecological impacts. In the agricultural groundwater revolution: opportunities and threats to development, Giordano M, Villholth KG (eds). CABI Publications: 7-36.

28. Shakoor, A., M. Arshad, A. Bakhsh and R. Ahmad (2015). GIS based assessment and delineation of groundwater quality zones and its impact on agricultural productivity. Pak. J. Agri. Sci., 52(3):837-843.

29. Shakoor, A., M. Arshad, A.R. Tariq and I. Ahmad. 2012. Evaluating the Role of Bentonite Embedment in Controlling Infiltration and Improve Root Zone Water Distribution in Coarse Soil. Pak. J. Agri. Sci., 49(3): 375-380.

30. Shakoor, A., Z.M. Khan, M. Arshad, H.U. Farid, M. Sultan, M. Azmat, M.A. Shahid and Z. Hussain. 2017. Regional groundwater quality management through hydrogeological modeling in LCC (West) Faisalabad Pakistan. Journal of Chemistry, 1-16. Doi: 10.1155/2017/2041648.

31. Shirazi, Sharif Moniruzzaman, H M Imran, and Akib Shatirah. 2012. "GIS-based DRASTIC Method for Groundwater Vulnerability Assessment: A Review." Journal of Risk Research 991-1011.

32. Zhonghua, T., A. M. Muhammad, A. S. Dawood and B. Earl (2015). "Evaluation of local groundwater vulnerability based on DRASTIC index method in Lahore, Pakistan". Geophysical international, Vol. 54-1: 67-81.

33. Bhatti, M. T., Anwar, A. A., \& Aslam, M. (2017). Groundwater monitoring and management: Status and options in Pakistan. Computers and Electronics in Agriculture, 135, 143-153. 